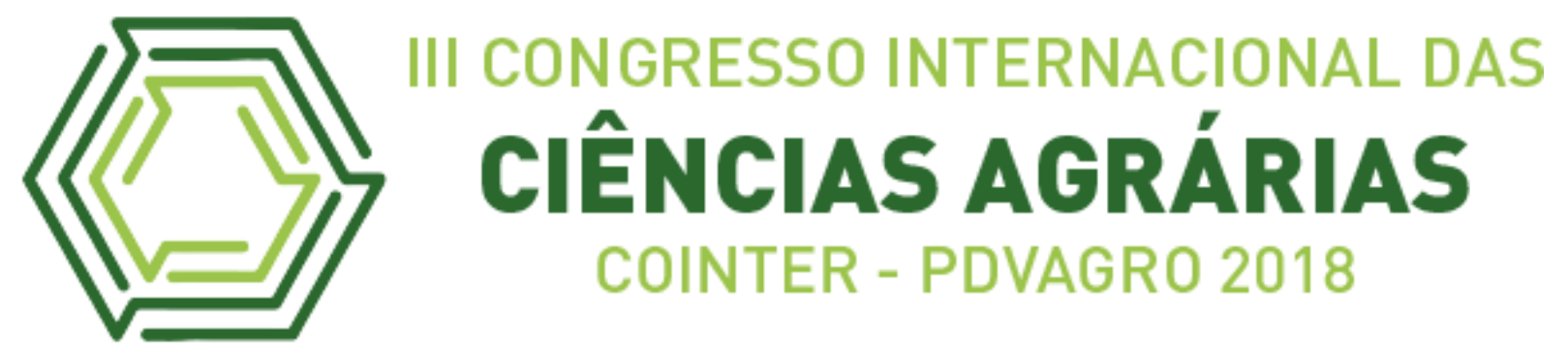

\title{
EMERGÊNCIA DE SEMENTES DE ABÓBORA DA CULTIVAR JACAREZINHO EM FUNÇÃO DE DIFERENTES SUBSTRATOS
}

\section{EMERGENCE OF PUMPKIN SEEDS OF CULTIVAR JACAREZINHO IN THE FUNCTION OF DIFFERENT SUBSTRATES}

\author{
Apresentação: Pôster \\ Gabriel da Silva Vasconcelos ${ }^{1}$; Benoliel Bulamarque Leite de Andrade ${ }^{2}$; Renan Lima \\ do Nascimento $^{3}$; Martinho Melo Figueiredo ${ }^{4}$; Luiz Augusto Silva de Sousa ${ }^{5}$ \\ DOI: https://doi.org/10.31692/2526-7701.IIICOINTERPDVAGRO.2018.00464
}

\section{Introdução}

O plantio das abóboras é feito através do semeio das sementes diretamente no solo, ou covas, variando de duas a três sementes por covas, ou plantio em viveiro quando se quer produzir mudas para depois levar ao local definitivo de cultivo. Este último método está sendo bastante difundido entre os agricultores, pois trás alguns benefícios, como: escolhas das melhores mudas para compor o seu plantio, plântulas mais sadias livres do ataque de pragas e doenças, diminuição de ataque de insetos às plântulas. Na maioria das vezes os agricultores utilizam o próprio material disponível em sua propriedade para produzir as mudas e o mais utilizado é a terra preta.

O tipo de substrato influencia diretamente no processo de germinação e emergência das sementes, por isso, identificar os substratos mais recomendados para o semeio das sementes é uma etapa muito importante na tomada de decisão do agricultor que poderá refletir diretamente no sucesso ou fracasso da atividade econômica.

Isto porque diversos fatores podem prejudicar a geminação e emergência das sementes de abóboras, dentre os quais se destacam fatores genéticos, físicos, fisiológicos e sanitários, que interferem na capacidade do lote de originar uma lavoura uniforme, constituída de plantas

\footnotetext{
${ }_{1}^{1}$ Agronomia, Universidade Federal Rural da Amazônia, gabrielvasconcelosagro@gmail.com

${ }^{2}$ Agronomia, Universidade Federal Rural da Amazônia, benoliel06@gmail.com

${ }^{3}$ Agronomia, Universidade Federal Rural da Amazônia, renannascimento025@gmail.com

${ }^{4}$ Agronomia, Universidade Federal Rural da Amazônia, martinhomelofigueiredo@gmail.com

${ }^{5}$ Doutor, Universidade Federal Rural da Amazônia, lassouza@gmail.com
} 
vigorosas, representativas do cultivar e livres de plantas invasoras ou indesejáveis. Entretanto, o efetivo potencial de um lote de sementes, quanto à sua capacidade germinativa, pressupõe ótimas condições ambientais no campo para o estabelecimento das plântulas. As condições ideais para a geminação são definidas principalmente pelo tipo de substrato que é de suma importância, pois fatores como estrutura, aeração, capacidade de retenção de água, grau de infestação de patógenos, dentre outros, podem interferir na germinação das sementes e desenvolvimento pós-seminal.

Entendendo a importância dessa cultura para a agricultura familiar, a motivação inicial que orientou o presente labor foi a de contribuir para a construção de um conhecimento científico no que diz respeito ao estudo dos melhores substratos para a produção de mudas de abóbora da cultiva jacarezinho, tendo em vista seu melhor desempenho vegetativo durante o ciclo da cultura.

Desta forma, o objetivo deste estudo foi avaliar o efeito dos diferentes tipos de substrato na emergência e desenvolvimento vegetativo de plântulas de sementes da abóbora da cultiva jacarezinho, em condições de casa de vegetação.

\section{Fundamentação Teórica}

A abóbora é uma hortaliça com grande aceitação pelo mercado consumidor paraense e está presente em feiras livres e grandes redes de supermercados locais. Além de muito apreciada pela culinária regional, segundo Daiuto (2012) possui importantes propriedades nutricionais como provitaminas A, vitaminas do complexo $\mathrm{B}$, carotenóide e vitamina $\mathrm{C}$ que são importantes antioxidantes.

A taxa de germinação das sementes está intimamente relacionada com a tensão de água no solo e com o período de absorção de água, entre outros fatores. É um processo caracterizado por uma sequência de eventos fisiológicos influenciados por fatores intrínsecos e extrínsecos às sementes. Dentre os fatores externos que exercem influência decisiva sobre o processo de germinação, são considerados como essenciais a água, a temperatura, o oxigênio e a luz (BORGES \& RENA, 1993). O tipo de substrato pode influenciar a disponibilidade desses fatores extrínsecos às sementes, bem como proporcionar condições físicas desejáveis para o desenvolvimento das mesmas.

Em condições de campo as plântulas ficam sujeitas ao ataque pragas e doenças que levam muitas vezes a necessidade de replantio em grandes áreas. Uma alternativa é a 
produção de mudas em viveiro e transplantá-las em campo com desenvolvimento vegetativo desenvolvido. Contudo, para produzir uma muda sadia, deve-se ter conhecimento do melhor substrato que proporcionará melhores condições de desenvolvimento, tais como: manejo adequado da água, melhores propriedades física e química, isenção de pragas e controle de ervas daninhas, além de contribuir no ato transplantio, para o melhor desenvolvimento das plantas (FERNANDES e CORA, 2001).

\section{Metodologia}

O estudo foi conduzido na Universidade Federal Rural da Amazônia, Campus BelémPA, no período de julho a setembro de 2018. O experimento foi instalado em casa de vegetação do grupo de pesquisa MIPDAM (Manejo Integrado de Plantas Daninhas da Amazônia) localizado nas seguintes coordenadas geográficas (latitude: $1^{\circ} 27^{\prime} 17,36$ " S e longitude: $\left.48^{\circ} 26^{\prime} 18,79^{\prime \prime} \mathrm{O}\right)$.

As sementes foram adquiridas em casa agropecuária idônea, com embalagem em lata de alumínio lacrada dentro do prazo de validade como estipulado pelo fabricante.

Os substratos foram preparados na casa de vegetação e em seguido colocados nas bandejas plásticas, separados pelos respectivos tratamentos. Os tratamentos foram os diferentes substratos, a saber: T1 - Terra Preta; T2 - Terra + Vermiculita; T3 - Terra + Serragem e T4 - Areia. O delineamento experimental foi inteiramente casualizado com quatro tratamentos e nove repetições.

Foram semeadas 100 sementes em cada tratamento, a cinco milímetros de profundidade em bandejas de plástico com 20 células, semeando uma semente por célula e foram realizadas duas regas diárias, uma pela manhã e outra à tarde.

O experimento ficou sob observação em casa de vegetação durante dez dias para observar o número de sementes que emergiram após o semeio, onde foi calculado o Índice de Valor de Emergência (IVE) calculada a partir da contagem diária do número de plântulas emergidas nos tratamentos e utilizando-se a equação: $\mathrm{IVG}=\mathrm{G} 1 / \mathrm{N} 1+\mathrm{G} 2 / \mathrm{N} 2+\ldots \mathrm{Gn} / \mathrm{Nn}$. Sendo:Gn número de sementes germinadas no n-ésimo dia; $\mathrm{N}$ - número de dias após a semeadura.

Em seguida as plântulas foram removidas e higienizadas para determinação da massa fresca em balança de precisão. Após determinação da massa fresca as plântulas foram acondicionadas em envelopes de papel e levadas à estufa em temperatura de $60^{\circ} \mathrm{C}$ 
permanecendo por 72 horas para determinação da matéria seca.

Os dados foram submetidos a Análise de Variância para verificar se os tratamento apresentaram diferenças significativas e as médias foram comparadas pelo Test-T para verificar se os tratamentos apresentaram diferenças entre si, ao nível de 5\% de probabilidade de erro.

\section{Resultados e Discussões}

A porcentagem de emergência variou nos quatro tratamentos, porém não apresentaram diferenças estatísticas significativas pela Análise de Variância e nem pelo Test-T de comparação de média. O T1 apresentou maior germinação com 88 sementes germinadas, seguido do T2, T3 e T4 com 86, 79 e 56 sementes, respectivamente. Os valores de emergência encontrado nos tratamentos T1 e T2 são relativamente altos com valores acima de $80 \%$ de emergência, indicando os referidos substratos apresentaram características químicas e físicas adequadas à emergência das plântulas. Este resultado pode está associado a maior capacidade de retenção de água pelo substrato Terra preta, favorecendo absorção pela semente e, por conseguinte o desenvolvimento do embrião, já os substrato T3 e T4 são caracterizado pela baixa capacidade de retenção de água, o que ter influenciado no desenvolvimento do embrião (Figura 1A).

A maior emergência ocorreu entre o quarto e sexto dia. No quarto dia, o T3 registrou maior número (24) de sementes emergidas, seguido do T1, T2 e T4 com 14, 12 e 9 sementes respectivamente. No dia seguinte, todos os tratamentos apresentaram os maiores números de sementes emergidas, com destaque para o T2 que registrou quase o dobro dos demais tratamentos. No sexto dia, o número de sementes que emergiram decresceu, ficando parecido ao quarto dia e diminuindo do sétimo ao decimo secundo dia, quando foi registrada a última semente emergida (Figura 1B).

O Tratamento T2 apresentou maior Índice de Velocidade de Emergência (IVE) a partir do quinto dia, seguido pelo $\mathrm{T} 1, \mathrm{~T} 3$ e $\mathrm{T} 4$, decrescendo em todos os tratamentos no dia seguintes até o décimo segundo dia. O resultado da Análise de Variância mostrou haver diferença significativa entre os dados, esta diferença foi observada quando se comparou as médias do T1, T2 T3 com o T4, não apresentando diferença significativa entre T1 e T2, T1 e T3 e T2 e T3 (Figura 2 A). 
Quanto ao peso da matéria fresca, o resultado da Analise de Variância mostrou haver diferença estatística significativa entre os tratamentos e o Teste de comparação de média revelou que todos os tratamentos diferenciaram-se entre si. O tratamento T2 foi o que apresentou maior média de peso fresco das plântulas de abóbora jacarezinho com 1,78g, seguido pelo T4, T1 e T3 com os respectivos valores 1,20, 1,02 e 0,82 g (Figura 2 B). Contudo vale lembrar que embora o T4 tenha apresentado a segunda maior média de peso de matéria fresca, foi a que registrou menor número de sementes emergidas entre os tratamentos.

Figura 1 - (A) Porcentagem de emergência; (B) Número de sementes emergidas; (C) Índice de Valor de Emergência e (D) Peso Médio de Matéria Fresca de plântulas de abóbora jacarezinho em diferentes substratos. T1 - terra preta; T2 - terra preta + vermiculita; T3 - vermiculita + serragem e T4 - areia. Belém, Pará, 2018.

Fonte: Própria

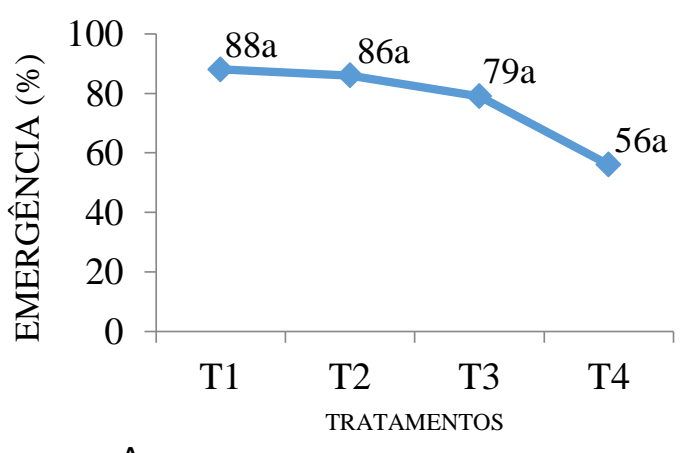

A

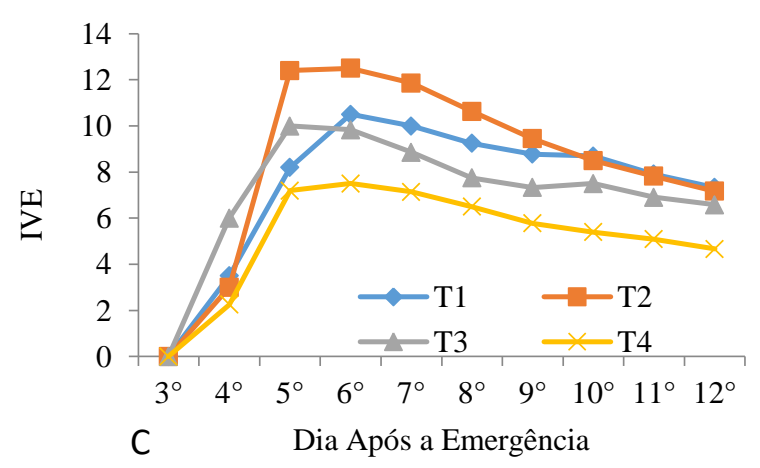

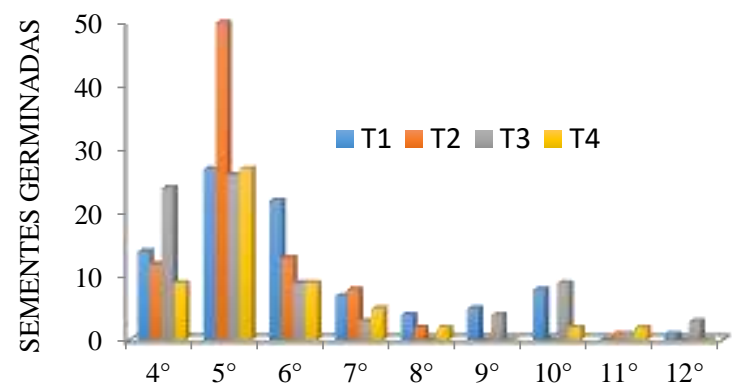

B

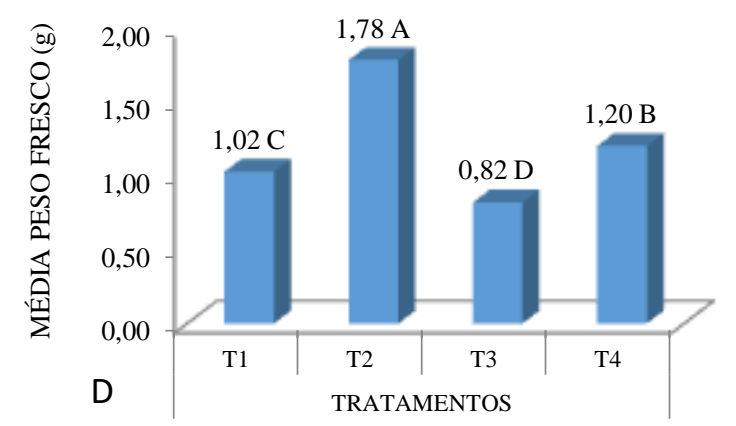

Letras iguais não apresenta diferença significativa a 5\% de probabilidade de erro no Test-T.

Esta velocidade de emergência pode está associada à melhora da estrutura física do substrato com adição de vermiculita à terra preta, deixando-o mais frouxo e leve, com maior entrada de ar nos macroporos, permitindo melhor trocas gasosas do embrião, favorecendo o seu desenvolvimento, além a retenção de água pela matéria orgânica de terra preta. No T1, embora apresente boa retenção de água, possui pouca porosidade quando comparado ao T2. 
Segundo Fernandes et al., (2006), cita que a maior proporção de partículas pequenas no substrato diminui a porcentagem de germinação das sementes, por dificultar a absorção de água nos primeiros dias após a semeadura e por prejudicar a aeração para as raízes após a quebra da tensão superficial.

Para Martins et al., (1999) Quanto mais tempo a plântula permanecer nos estádios iniciais de desenvolvimento e demorar a emergir no solo, mais vulnerável estarão às condições adversas do meio. A rápida germinação e desenvolvimento das sementes são características requeridas pelos produtores. Portanto, procuram-se meios para que esses fatores sejam influenciados beneficamente (SALES et al., 2015).

Os tratamentos T3 e T4 são substratos praticamente inertes, com baixa capacidade de retenção hídrica, o que pode ter afetado o IVE, os baixos números de sementes emergidas e a porcentagem de emergência.

\section{Conclusões}

Nas condições que este estudo foi desenvolvido pode concluir que o tratamento T2 (terra preta + vermiculita) foi o mais indicado para produção de mudas de abóbora jacarezinho, pois apresentou elevada porcentagem de emergência, maior germinação ao quinto dia após semeio, maior Índice de Valor de Emergência e maior desenvolvimento vegetativo das plântulas.

\section{Referências}

BORGES, E. E.; RENA, A. B. Germinação de sementes. In: AGUIAR, I. B; PINARODRIGUES, F. C. M.; FIGLIOLIA, M. B. Sementes florestais tropicais, Brasília: ABRATES. p. 83 - 127. 1993.

DAIUTO, É. R. Alterações nutricionais em casca e sementes de abóbora decorrentes de diferentes métodos de cozimento. Revista Iberoamericana de Tecnologia. Postcosecha. V. 13, num. 2. P. 196-203, 2012.

FERNANDES, C; CORÁ, J. E; BRAZ, L. T. Alterações nas propriedades físicas de substratos para cultivo de tomate cereja, em função de sua reutilização. Horticultura brasileira, p. 94-98, 2006.

Sales, M. A. L; Moreira, F. J. C.; Ribeiro, A. A.; Monteiro, R. N. F.; Sales, F. A. L. Potencial das sementes de abóbora submetidas a diferentes períodos de embebição. Brazilian Journal of Biosystems Engineering v. 9(4): 289-297, 2015. 
MARTINS, J. D; NAKAGAWA, J.; BOVI, M. L. Efeito da posição da semente no substrato e no crescimento inicial das plântulas de palmito-vermelho (Euterpe espiritosantensis Fernades - Palmae). Revista Brasileira de sementes, Brasília, v. 21, p. 164 - 173. 1999. 